\title{
Proposta de análise de falhas na coleta de informações para a avaliação de programas de pós-graduação baseada no FMEA
}

Érica Kushihara Akim

ericakim@ufscar.br

Ricardo Coser Mergulhão

mergulhao@ufscar.br

Miguel Ángel Aires Borrás

maborras@ufscar.br

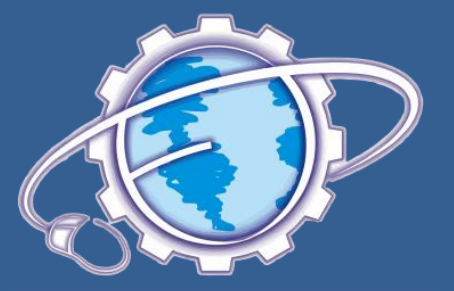

\section{RESUMO}

No Brasil, a avaliação dos programas de pós-graduação stricto sensu é efetuada pela Coordenação de Aperfeiçoamento de Pessoal de Nível Superior (CAPES) e compreende a realização de acompanhamento anual $e$ de avaliação trienal dos programas. Nesse processo avaliativo, a CAPES usa dados informados pelos programas de pós-graduação no aplicativo denominado "Coleta Capes" sobre suas atividades desenvolvidas no período avaliado. Um método que visa aumentar a confiabilidade dos processos pela prevenção de falhas é o FMEA, do inglês Failure Modes and Effects Analysis. Esse método é amplamente difundido na manufatura, mas pouco estudado no setor de serviços. Nesse sentido, o objetivo deste artigo foi desenvolver uma proposta para análise de falhas nas informações destinadas à avaliação de programas de pós-graduação, utilizando-se uma análise documental e de conteúdo. A elaboração desta proposta envolveu a adaptação dos elementos do FMEA, como escala de gravidade, ocorrência, detecção e outros, para o uso no Coleta CAPES. Após a apresentação da proposta, foi feita uma exemplificação do seu uso em um dos documentos temáticos do Coleta CAPES.

Palavras-chave: Confiabilidade; CAPES; FMEA; Pós-graduação.

\section{Proposal for Failure Analysis in Information Collection for Evaluation of the Graduate Program Based on FMEA}

\begin{abstract}
In Brazil, the assessment of the graduate programs is conducted by CAPES and includes conducting annual monitoring and triennial assessment of the programs. The CAPES uses information entered by graduate programs in application named "Coleta CAPES" about its activities in the period assessed. A method to increase the process reliability through failures prevention is FMEA (Failure Modes and Effects Analysis). It is widely used in the manufacturing sector, however the literatures regarding to the FMEA in service are not widely found. Therefore, the purpose of this article is to develop an approach for fault analysis on the assessment information programs graduate programs through a documentary analysis and content analysis. The development of this framework involved the adjustment of the FMEA elements, such as severity scale, occurrence, detection and others for use in the "Coleta CAPES". Thereafter is exemplification this framework on the issues paper of "Coleta CAPES".
\end{abstract}

Keywords: Reliability; CAPES; FMEA; Graduate. 


\section{Introdução}

A pós-graduação brasileira parece viver um processo de crescimento, sendo reconhecida pela comunidade científica nacional e internacional devido à sua expansão contínua e com qualidade até 2009 (SANTOS; AZEVEDO, 2009). O número de cursos de mestrado acadêmico, mestrado profissional e doutorado distribuídos apresentou taxa de crescimento de $49 \%$ no período de 2001 a 2011, segundo dados da Coordenação de Aperfeiçoamento de Pessoal de Nível Superior CAPES (2013).

A avaliação dos programas de pósgraduação no Brasil, conduzida pela CAPES, permitiu comparar o nível das atividades de pesquisa entre os programas nacionais de pósgraduação, levando em conta a estrutura, o corpo docente e discente, as atividades de ensino e pesquisa, bem como a produção intelectual, teses e dissertações de cada programa. Essa avaliação é alimentada por dados e informações sobre as atividades desenvolvidas pelos programas de pósgraduação exportados anualmente à CAPES, por meio de um aplicativo denominado Coleta de Dados CAPES (CAPES, 2011a), que aqui será denominado como Coleta CAPES. Esse conjunto de dados e informações é considerado na análise dos indicadores de qualidade dos programas de pósgraduação e as informações também são utilizadas no planejamento dos programas de fomento $\mathrm{e}$ delineamento das políticas institucionais dessa agência (CAPES, 2012a).

Com o quadro recente de expansão do sistema de pós-graduação stricto sensu e da importância de sua avaliação pela CAPES, faz-se importante que os programas de pós-graduação busquem meios para aumentar a confiabilidade das informações a ela enviadas.

Esse envio de informações é efetuado via sistema constituído de um conjunto de atividades com entradas e saídas, que podem ser analisados via método do FMEA, de forma que seja possível apontar os modos de falhas, suas causas e efeitos e, sobretudo, estabelecer ações preventivas ao invés de ações corretivas no processo de coleta e envio das informações. Uma pesquisa bibliométrica, apresentada mais adiante, constatou uma carência de trabalhos relacionados a esse tema.

O estudo para aumento de confiabilidade desse sistema pode ser desenvolvido utilizando o FMEA (do inglês Failure Modes and Effects
Analysis), que se constitui em método que possibilita avaliar de forma lógica os possíveis tipos de falha aos quais dado sistema está sujeito, possibilitando que ações preventivas sejam efetuadas para evitar os efeitos negativos possivelmente causados pelas falhas detectadas.

$\mathrm{O}$ envio das informações à CAPES consiste de um conjunto de atividades com entradas e saídas que pode ser analisado via método do FMEA, de forma que seja possível apontar os modos de falhas, suas causas e efeitos e, sobretudo, estabelecer ações preventivas ao invés de ações corretivas no processo de coleta e envio das informações. Uma pesquisa bibliométrica, apresentada mais adiante, constatou uma carência de trabalhos relacionados a esse tema.

Dentro do contexto apresentado, este artigo teve como objetivo o desenvolvimento de uma proposta de uso do FMEA na análise de falhas das informações destinadas à avaliação de programas de pós-graduação, buscando aprofundar a compreensão sobre a relação entre entre os dados inseridos no aplicativo Coleta CAPES e o sistema de avaliação coordenado pela CAPES e proporcionando um método que contribua para o incremento da confiabilidade do processo de coleta de dados por dado programa de pós-graduação.

\section{Avaliação de Programas de pós-graduação e do Coleta CAPES}

\subsection{Análise Bibliométrica}

Com o objetivo de contextualizar e conceituar este artigo, esta seção apresenta o resultado da pesquisa bibliométrica acerca dos estudos sobre o tema avaliação da pós-graduação conduzida pela CAPES.

A análise bibliométrica objetivou investigar o curso de determinada disciplina por meio de métodos estatísticos e matemáticos. Entre suas possibilidades está a identificação de tendências e crescimento do conhecimento em determinada disciplina (SPINAK, 1998).

Para Vianna et al. (2011) é fundamental, ao se realizar a busca, considerar que quanto mais um trabalho é utilizado como referência para outros em determinado intervalo de tempo, maior o seu impacto científico.

Foi realizada uma pesquisa, em outubro de 2012, sobre o tema Avaliação de Programas de PósGraduação coordenada pela CAPES na base de 
dados Web of Science - ISI (2012), com os termos "evaluation e CAPES" ou "assessment e CAPES", no período de 1945 a 2012.

A partir das 37 referências identificadas, foi excluída uma delas, que representava um Editorial, mantendo-se apenas os artigos. Em seguida, por meio de análise de conteúdo, foram lidos os títulos e resumos com o propósito de verificar a aderência deles ao tema pesquisado.

Excluídos os artigos cujos resumos não estavam alinhados com o tema avaliação de programa de pós-graduação coordenado pela CAPES, o conjunto amostral foi reduzido a 13 artigos, que podem ser conferidos no Quadro 1.

Quadro 1 - Citações de referências em textos acadêmicos na Web of Science - ISI no período de 2003 a 2012.

\begin{tabular}{|c|c|c|c|}
\hline Referência & Assunto & Periódico & Citações \\
\hline Barros (2006) & $\begin{array}{l}\text { O artigo descreve o panorama de expansão da pós- } \\
\text { graduação em saúde coletiva e discute aspectos } \\
\text { dos critérios de sua avaliação. }\end{array}$ & $\begin{array}{l}\text { Revista de Saúde } \\
\text { Pública }\end{array}$ & 11 \\
\hline Gama et al. (2003) & $\begin{array}{l}\text { Analisa o progresso da área de pós-graduação em } \\
\text { Química no período de } 1998 \text { a 2001, apresentando } \\
\text { um quadro positivo no quadro de alunos e no } \\
\text { número de programas. }\end{array}$ & Química Nova & 6 \\
\hline Tess et al. (2009) & $\begin{array}{l}\text { Analisa a avaliação da produção intelectual do } \\
\text { Instituto do Coração. }\end{array}$ & Clinics & 5 \\
\hline Minayo (2010) & $\begin{array}{l}\text { Debate sobre o desempenho da pós-graduação em } \\
\text { Saúde Coletiva no período de } 1997 \text { a } 2007 .\end{array}$ & $\begin{array}{l}\text { Ciência \& Saúde } \\
\text { Coletiva }\end{array}$ & 2 \\
\hline Ruiz et al. (2009) & $\begin{array}{l}\text { Apresenta e discute sobre os instrumentos } \\
\text { bibliométricos e a sua importância na aferição da } \\
\text { qualidade dos periódicos científicos. }\end{array}$ & $\begin{array}{l}\text { Revista Brasileira de } \\
\text { Cirurgia } \\
\text { Cardiovascular }\end{array}$ & 2 \\
\hline Erdmann et al. (2009) & $\begin{array}{l}\text { Identifica a indexação das revistas da área da } \\
\text { Enfermagem, editadas no Brasil, nas principais } \\
\text { bases bibliográficas das áreas da Saúde e } \\
\text { Enfermagem. }\end{array}$ & $\begin{array}{l}\text { Revista Latino- } \\
\text { Americana de } \\
\text { Enfermagem }\end{array}$ & 2 \\
\hline $\begin{array}{l}\text { Hortale e Moreira } \\
\text { (2008) }\end{array}$ & $\begin{array}{l}\text { Discute as características e limitações da avaliação } \\
\text { interna ou autoavaliação dos programas de pós- } \\
\text { graduação stricto sensu da área de Saúde Coletiva. }\end{array}$ & $\begin{array}{l}\text { Ciência \& Saúde } \\
\text { Coletiva }\end{array}$ & 1 \\
\hline Pinto e Cunha (2008) & $\begin{array}{l}\text { Discute o uso do Fator de impacto na avaliação de } \\
\text { programas de pós-graduação em Química pela } \\
\text { CAPES e a internacionalização da produção } \\
\text { intelectual brasileira. }\end{array}$ & Química Nova & 1 \\
\hline Munari et al. (2011) & $\begin{array}{l}\text { Caracteriza a produção da pós-graduação brasileira } \\
\text { na área da Enfermagem no triênio 2007-2009. }\end{array}$ & $\begin{array}{l}\text { Revista da Escola de } \\
\text { Enfermagem da USP }\end{array}$ & 0 \\
\hline Meneghini (2011) & $\begin{array}{l}\text { Propõe algoritmo para pesar indicadores } \\
\text { cientométricos que devem ser considerados na } \\
\text { avaliação de uma instituição científica. }\end{array}$ & $\begin{array}{l}\text { Brazilian Journal Of } \\
\text { Medical and } \\
\text { Biological Research }\end{array}$ & 0 \\
\hline $\begin{array}{l}\text { Marchlewski et al. } \\
\text { (2011) }\end{array}$ & $\begin{array}{l}\text { Analisa os principais pontos de debates sobre o } \\
\text { impacto do sistema de avaliação da pós-graduação } \\
\text { na produção intelectual em Educação Física a } \\
\text { partir de artigos em periódicos da área entre } 2006 \\
\text { e } 2009 \text {. }\end{array}$ & $\begin{array}{l}\text { Motriz-Revista de } \\
\text { Educação Física }\end{array}$ & 0 \\
\hline $\begin{array}{l}\text { Machado e Zaher } \\
\text { (2010) }\end{array}$ & $\begin{array}{l}\text { Explora o impacto do sistema Qualis na avaliação } \\
\text { CAPES na área de Zoologia. }\end{array}$ & Zoologia & 0 \\
\hline Viacava (2010) & $\begin{array}{l}\text { Analisa a evolução ao longo dos triênios dos } \\
\text { periódicos mais frequentemente usados na área de } \\
\text { Saúde Coletiva, número de autores, idioma, } \\
\text { nacionalidade das revistas e cooperação } \\
\text { interregional. }\end{array}$ & $\begin{array}{l}\text { Ciência \& Saúde } \\
\text { Coletiva }\end{array}$ & 0 \\
\hline
\end{tabular}

Fonte: Elaboração própria. 
Em relação à amostra, o periódico "Ciência \& Saúde Coletiva" contempla $22 \%$ dos artigos pertinentes ao tema pesquisado, seguido pelo periódico "Química Nova" com 15\%.

Relativo à área de produção científica, notase a predominância em torno da área da Saúde Coletiva e Ciências Médicas. Outras áreas representativas são a Ciências Biológicas e a Química.

As referências identificadas no Web of Science - ISI indicam que a avaliação da pós-graduação realizada pela CAPES é um tema recente e com número reduzido de publicações, sendo estes concentrados (46\%) no último biênio (2010 e 2011), conforme pode ser constado na Figura 1.

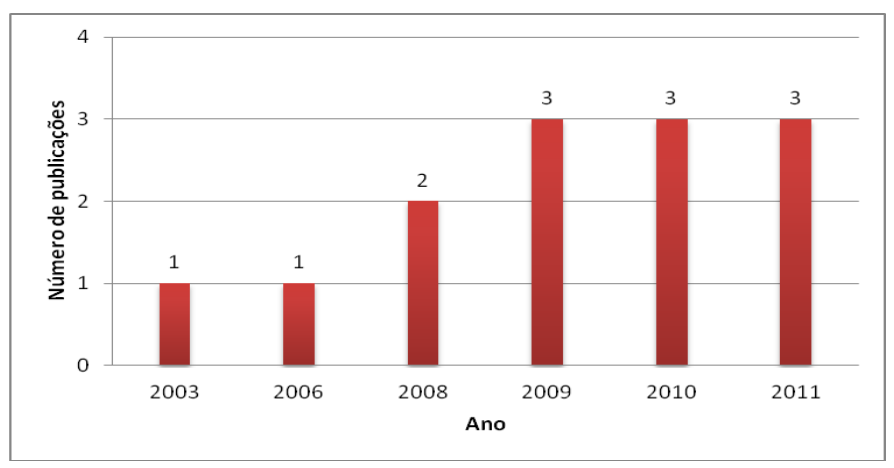

Figura 1 - Evolução temporal dos artigos ISI of Web.

Fonte: Elaboração própria.

Observa-se o predomínio, nas referências selecionadas (Quadro 1), de palavras-chave relacionadas a indicadores de produção científica, demonstrando o interesse dos pesquisadores sobre a influência da produção intelectual na avaliação dos programas de pós-graduação. A polarização em torno dos critérios de avaliação da produção intelectual foi confirmada pela leitura dos 13 artigos.

Para categorização das referências selecionadas no Web of Science - ISI dentro do tema Avaliação da Pós-Graduação realizada pela CAPES, foi considerada a classificação seguinte:

-"Entrada": nesta categoria são englobados os artigos que abordam a coleta de informações anual por meio do Coleta CAPES.

-"Avaliação": quando o artigo aborda o tratamento e análise das informações fornecidas pelos programas de pós-graduação, englobando as discussões sobre os critérios adotados na avaliação.

-"Saídas": consistem em artigos cujo foco central está na análise e comparação dos resultados da avaliação realizada pela CAPES.

Após a leitura dos artigos, estes foram agrupados em categorias, conforme os assuntos abordados. A maior parte dos trabalhos, representando 77\%, apresenta, sobretudo, as discussões sobre os critérios adotados pela CAPES na avaliação do programa de pós-graduação, em especial sobre o uso do fator de impacto na avaliação de periódicos. Nota-se também a existência de artigos que descrevem o processo de avaliação dentro de uma área específica (BARROS, 2006) e de estudo sobre os procedimentos de autoavaliação adotados pelos programas de pósgraduação (HORTALE; MOREIRA, 2008).

Já a categoria "Saída", que corresponde a $29 \%$ dos artigos, apresenta trabalhos sobre o desempenho de programas de pós-graduação, considerando uma área de avaliação e período específicos (MINAYO, 2010; GAMA et al., 2003). Nessa categoria também constam artigos com o objetivo de caracterizar a produção intelectual de determinada área de avaliação (VIACAVA, 2010).

Considerando os objetivos deste artigo, segundo a categorização das referências apresentada, ele está situado na categoria "Entrada". Não foram encontrados trabalhos, entre os selecionados no $\mathrm{Web}$ of Science - ISI, que tenham como objeto o processo de coleta de informações por meio do Coleta CAPES. Apenas três artigos citam o aplicativo Coleta CAPES, reforçando a percepção de que o tema é pouco explorado.

Gama et al. (2003) mencionaram de forma direta a utilização do aplicativo Coleta CAPES. Esses autores afirmaram que o Comitê de Avaliação na área de Química verifica cuidadosamente a consistência das informações consideradas prioritárias, particularmente a produção científica em periódicos. Neste artigo, menciona-se como falhas operacionais do Coleta CAPES o não reconhecimento de periódicos, como consequência da falta de uniformidade no registro da informação ou na maneira de registrá-lo.

Já o artigo de Minayo (2010), com duas citações, trata do desempenho de programas de pósgraduação em saúde coletiva no período de 1997 a 2009. A mesma autora alertou para a necessidade de que a CAPES invista na criação de indicadores específicos à internacionalização dos programas, pois os relatórios dos programas em Saúde Coletiva apresentam informações pouco consistentes e juntamente com ausência de informações relevantes devido à forma voluntarista, amadorística e assistemática de coleta e tratamento dos dados nos relatórios da CAPES, mencionando o Coleta CAPES. 
Viacava (2010), que utilizou informações do Coleta CAPES em sua pesquisa, afirmou que o aplicativo ressente de problemas de incompletude de vários campos, como palavras-chave para definição de áreas temáticas da produção intelectual. Esse autor relatou em sua pesquisa a existência de problemas de duplicidade de artigos registrados no Coleta CAPES, apresentando problemas relacionados à falta de críticas na entrada dos dados e à falta de padronização na grafia de títulos de artigos e periódicos.

Como resultado da análise de conteúdo sobre os artigos identificados na análise bibliométrica, observou-se a existência de dificuldades na coleta e tratamento dos dados utilizados durante a avaliação, problemas esses relacionados à falta de uniformidade no registro da informação (GAMA et al., 2003), à forma voluntarista e assistemática de coleta e tratamento dos dados (MINAYO, 2010) e à existência de problemas de duplicidade de artigos e falta de críticas na entrada de dados (VIACAVA, 2010).

Evidencia-se que a pesquisa na base de dados Web of Science - ISI não retornou relatos de experiências, propostas e tendências relativas ao uso do aplicativo Coleta CAPES, indicando a existência de uma lacuna a ser preenchida.

\subsection{Avaliação da pós-graduação e o Coleta CAPES}

Quando da sua criação, em 1951, pelo Decreto $n^{\circ}$ 29.741, a Coordenação de Aperfeiçoamento de Pessoal de Nível Superior tinha como objetivo "assegurar a existência de pessoal especializado em quantidade e qualidade suficientes para atender às necessidades dos empreendimentos públicos e privados que visam ao desenvolvimento do país" (CAPES 2012c).

Em 1992, a CAPES é instituída como fundação pública pela Lei $n^{\circ} 8.405$ e tem os seus objetivos ampliados, passando a subsidiar o Ministério da Educação (MEC) na formulação de políticas de pós-graduação, a coordenar e avaliar cursos e a estimular, mediante a concessão de bolsas de estudo e auxílios, a formação de recursos humanos.

Para atingir os objetivos, a CAPES adota um sistema de avaliação caracterizado por três eixos:

-Feitos por pares, oriundos das diferentes áreas do conhecimento e reconhecidos por sua reputação intelectual;

-Tem natureza meritocrática, levando à classificação nos campos disciplinares; e,

-Associa reconhecimento e fomento, definindo políticas e estabelecendo critérios para o financiamento dos programas (CAPES, 2010b).

Para Steiner (2005), a avaliação é parte essencial da vida acadêmica. Ele afirmou que em um sistema educacional robusto a avaliação institucional é fundamental para dar transparência aos usuários e à sociedade.

Segundo Maccari et al. (2008), a preocupação com a qualidade dos cursos de nível superior surge em um contexto de desajuste entre Estado, instituição de ensino superior e sociedade. As avaliações surgem como respostas a uma dupla necessidade: do Estado, no sentido de orientar os financiamentos e canalizar as pressões que recebe da sociedade; e das universidades no sentido de evitar o perigo duplo: evitando se mostrarem incapazes de responder a essas pressões; e o de passarem a atender a todas as pressões imediatistas, prejudicando suas funções de desenvolver a pesquisa científica quanto o estudo das humanidades (DURHAM, 1992).

Para Durham (1992), na utilização ampla de avaliação por pares reside a garantia da participação da própria comunidade acadêmica no processo de avaliação, participação que não pode ser confundida com autoavaliação. Ainda, segundo essa autora, em muitos países o sistema de financiamento de pesquisas é orientado por critérios de mérito que constituem indiretamente uma forma permanente de avaliação dos centros de produção científica nas universidades.

No sistema de avaliação adotado pela CAPES, os diferentes cursos e programas de pósgraduação obedecem a uma matriz comum de critérios de avaliação, denominada "Ficha de Avaliação". Há uma ficha para programas acadêmicos e outra para os mestrados profissionais (CAPES, 2013). Para garantir a classificação nos campos disciplinares, cada área de avaliação tem liberdade para definir a ponderação dos itens que compõem essa ficha.

Já o Coleta CAPES consiste no aplicativo onde as informações sobre as atividades desenvolvidas pelo programa são armazenadas e exportadas do programa de pós-graduação para Reitoria ou Pró-Reitoria, que por sua vez, transfere esses dados à CAPES por meio do sistema CAPESNet. Os prazos para a realização dessas atividades são estabelecidos em Portaria publicada pela CAPES no Diário Oficial da União.

As informações relativas a cada programa 
de pós-graduação são agrupadas no Coleta CAPES em 11 documentos temáticos, cujas funções são apresentadas no Quadro 2, sendo eles: Programas; Disciplinas; Cursos; Turmas; Cadastros; Trabalhos de Conclusão; Proposta do Programa; Produção Intelectual; Linhas de Pesquisa; Fluxo Discente; e Projetos (CAPES, 2009).

Quadro 2 - Documentos Temáticos do Coleta CAPES

\begin{tabular}{|c|c|}
\hline Documentos Temáticos & Função \\
\hline Programas & $\begin{array}{l}\text { Registra as informações gerais e comuns aos cursos do Programa, como endereço, áreas de } \\
\text { concentração. }\end{array}$ \\
\hline Disciplinas & $\begin{array}{l}\text { Registra os dados das disciplinas que compõem a estrutura curricular dos cursos do } \\
\text { Programa. }\end{array}$ \\
\hline Cursos & $\begin{array}{l}\text { Registra as informações e dados gerais dos cursos, como dados do coordenador, créditos } \\
\text { para titulação. }\end{array}$ \\
\hline Turmas & Registra as informações de oferta de disciplina (turma) durante o ano-base. \\
\hline Cadastros & $\begin{array}{l}\text { Registra as informações sobre as pessoas referenciadas no ano-base, podendo ser } \\
\text { classificadas em docentes, discentes e participantes externos. }\end{array}$ \\
\hline Trabalhos de Conclusão & $\begin{array}{l}\text { Registra as Dissertações e Teses defendidas e aprovadas nos cursos do Programa durante o } \\
\text { ano-base. }\end{array}$ \\
\hline Proposta do Programa & $\begin{array}{l}\text { Registra a concepção acadêmica do Programa, além de críticas e sugestões referentes ao } \\
\text { aplicativo e ao processo de avaliação. }\end{array}$ \\
\hline Produção Intelectual & $\begin{array}{l}\text { Registra a produção bibliográfica, técnica e artística realizada no Programa durante o ano- } \\
\text { base. }\end{array}$ \\
\hline Linhas de Pesquisa & Registra as informações gerais sobre a linha de pesquisa. \\
\hline Fluxo Discente & $\begin{array}{l}\text { Visualiza o fluxo de alunos dos cursos do Programa, representado pela diferença entre } \\
\text { entrada e saída de alunos durante o ano-base, considerando os alunos novos e antigos, a } \\
\text { evasão, a titulação e a mudança de nível do mestrado para o doutorado. }\end{array}$ \\
\hline Projetos & $\begin{array}{l}\text { Registra as informações gerais sobre os projetos do Programa, desenvolvidos ou em } \\
\text { desenvolvimento no ano-base. }\end{array}$ \\
\hline
\end{tabular}

Fonte: Adaptado de CAPES, 2012a.

Os dados coletados foram agrupados em "Cadernos de Indicadores", que são os relatórios disponibilizados para avaliação propriamente dita, sendo eles:

- Teses e Dissertações: Relacionam-se às teses e dissertações defendidas no ano avaliado.

- Produção Bibliográfica: Destacam-se as cinco melhores produções bibliográficas selecionadas pelo Programa e relacionam a produção bibliográfica de docentes, discentes e egressos do Programa.

- Produção Técnica: Destacam-se as cinco melhores produções técnicas selecionadas pelo Programa e relacionam a produção técnica de docentes, discentes e egressos do Programa.

- Produção Artística: Destacam as cinco melhores produções artísticas selecionadas pelo Programa e relacionam a produção artística de docentes, discentes e egressos do Programa;

- Corpo Docente, Vínculo e Formação:
Relacionam-se os docentes permanentes e colaboradores do Programa, informando dados de vinculação com o Programa, dados da titulação e situação em outros programas de pós-graduação.

- Disciplinas: Relacionam-se as disciplinas que integram o currículo dos cursos ofertados no Programa, indicando a carga horária, número de créditos, ementa, bibliografia e informações sobre a oferta da disciplina no ano avaliado, como semestre de oferta e dados dos docentes responsáveis pela oferta.

- Linhas de Pesquisa: Relacionam-se as Linhas de Pesquisa do Programa, informando a descrição, a área de concentração e os Projetos de Pesquisa vinculados à Linha de Pesquisa, com informações sobre a sua situação e sua natureza.

- Projetos de Pesquisa: Relacionam-se os projetos de pesquisa em andamento no ano 
avaliado, informando a sua descrição, a área de concentração, a quantidade de alunos envolvidos e dados da sua equipe e do seu financiamento.

- Proposta do Programa: Apresentam-se as informações prestadas pelo Programa de PósGraduação sobre a visão geral, evolução e tendências do Programa, a integração com a graduação, a infraestrutura, intercâmbios, pontos fortes e fracos do programa, ensino a distância, trabalhos em preparação, atividades complementares, solidariedade, nucleação e visibilidade.

- Atuação do Corpo Docente: Apresentam-se os indicadores de atuação de cada docente, informando dados sobre oferta de disciplina(s) na graduação e na pós-graduação, participação em projeto de pesquisa, orientações e participação em bancas examinadoras.

- Produção do Corpo Docente: Apresentam-se os indicadores de produção bibliográfica, técnica e artística dos docentes que orientaram e, ou, ministraram disciplinas no ano avaliado.

As informações prestadas por meio do aplicativo da CAPES são de suma importância no processo de avaliação, pois subsidiam a elaboração dos indicadores para acompanhamento e avaliação dos Programas de Pós-Graduação. Nesse contexto, destaca-se a influência entre qualidade dos dados inseridos no Coleta CAPES e a qualidade dos indicadores gerados, justificando o estudo de alternativas de redução de falhas durante o processo de coleta de dados.

\subsection{Análise de modos e efeitos de falha (FMEA)}

De acordo com Fernandes e Rebelato (2006), o método FMEA avalia a severidade de cada falha relativamente ao impacto causado dos clientes, sua probabilidade de ocorrência e de detecção antes de chegarem às mãos aos clientes. Com base nesses três elementos: severidade, ocorrência e detecção, o método FMEA leva à priorização de quais modos de falha levam a um maior risco ao cliente e que, portanto, merecem atenção.

Segundo Stamatis (1995), há quatro tipos de FMEA, classificados de acordo com o tipo de aplicação: FMEA de Sistemas, usado na análise de sistemas em fase de concepção ou projeto; de Projeto, utilizado em projetos antes que virem produtos; de Processo, usado na análise de processos de produção; e de Serviço, utilizado na análise de serviços antes que estes cheguem ao consumidor.

Análises semelhantes ao FMEA são utilizadas há muitos anos, mas o método foi formalmente desenvolvido pela NASA (sigla em inglês de National Aeronautics and Space Administration), em 1963. No entanto, o método passou a ser mais utilizado quando a Ford Motor Company o introduziu na fabricação de seus automóveis, em 1997 (GUZZON, 2009).

A utilização do FMEA foi ampliada na década de 1990, diante da adoção desse método na Norma QS 9000, como padrão para os fornecedores automotivos (HECKERT et al., 1998).

Aplicações do FMEA têm sido relatadas por pesquisadores de diversas áreas:

- Distribuição de energia elétrica (SANT 'ANNA; PINTO JÚNIOR, 2011).

- Impactos ambientais durante o processo produtivo (ZAMBRANO; MARTINS, 2007).

- Serviços hospitalares (HO; LIAO, 2011).

- Serviços contábeis (PINHO; AZEVEDO, 2008).

- Sistemas agroindústrias (ROSA; GARRAFA, 2009; BARROS; MILAN, 2010).

- Transporte terrestre e aéreo de passageiros e cargas (ROOS et al., 2008).

$\mathrm{Na}$ área ambiental, autores como Zambrano e Martins (2007) afirmaram que a utilização do FMEA para o levantamento de impactos ambientais pode propiciar o aprendizado ao pequeno empresário sobre o conceito de gestão de processos. Apontaram também que o método é de fácil utilização e pode ser entendido por vários funcionários da organização.

Sant Anna e Pinto Júnior (2011), em estudo sobre as falhas nas linhas de transmissão de energia elétrica relataram que o FMEA auxiliou no aumento da confiabilidade do sistema de transmissão de energia, demonstrando ser um instrumento eficaz na identificação das ações recomendadas para eliminar os problemas causadores das falhas dos isoladores.

$\mathrm{Na}$ área médica, o artigo de Ho e Liao (2011) relatara a utilização do FMEA na avaliação do risco na eliminação de resíduos hospitalares.

Pinho e Azevedo (2008) destacaram a facilidade de adaptação do FMEA no setor contábil e o baixo custo envolvido na aplicação. Esses autores afirmaram que a solução de problemas se apresentou de forma mais clara, adequando $o$ processo de serviço rumo a um melhor resultado. 
A execução do FMEA é centrada na aplicação de um formulário desenvolvido de acordo com o critério de cada empresa, não existindo padronização (SAKURADA, 2001). Para esse autor, há pouca variação entre os procedimentos para o desenvolvimento do FMEA, conforme apresentado no Quadro 3, que compara as etapas propostas por pesquisadores do FMEA.

Quadro 3- Procedimentos para o desenvolvimento do FMEA

\begin{tabular}{|c|c|c|c|c|}
\hline Etapas & $\begin{array}{c}\text { Teng; Ho } \\
\text { (1996) }\end{array}$ & $\begin{array}{l}\text { Kume } \\
(1996)\end{array}$ & $\begin{array}{l}\text { Villacourt } \\
(1992)\end{array}$ & $\begin{array}{l}\text { Stamatis } \\
(\mathbf{1 9 9 5})\end{array}$ \\
\hline 1 & $\begin{array}{l}\text { Coleta de } \\
\text { informações do } \\
\text { componente e função } \\
\text { do processo }\end{array}$ & Modos de falha & $\begin{array}{l}\text { Revisar as } \\
\text { especificações e } \\
\text { documentos de } \\
\text { requerimentos do } \\
\text { sistema }\end{array}$ & $\begin{array}{l}\text { Selecionar a equipe e } \\
\text { Brainstorming }\end{array}$ \\
\hline 2 & Modos de falha & Efeitos & Coletar as informações & $\begin{array}{l}\text { Diagrama funcional de blocos } \\
\text { e ou fluxograma do processo }\end{array}$ \\
\hline 3 & Efeitos & $\begin{array}{l}\text { Causas e mecanismos } \\
\text { das falhas }\end{array}$ & $\begin{array}{l}\text { Diagrama funcional de } \\
\text { blocos }\end{array}$ & $\begin{array}{l}\text { Organizar os problemas por } \\
\text { prioridade }\end{array}$ \\
\hline 4 & Causas & Ocorrência & Modos de falha & Modos de falha \\
\hline 5 & Controles atuais & Severidade & Efeitos & Efeitos \\
\hline 6 & $\begin{array}{l}\text { NPR (Número de } \\
\text { prioridade de risco) }\end{array}$ & Detecção & Causas & Controles existentes \\
\hline 7 & Ações corretivas & $\begin{array}{l}\text { NPR (Número de } \\
\text { prioridade de risco) }\end{array}$ & $\begin{array}{l}\text { Controles atuais, } \\
\text { detecção das falhas }\end{array}$ & $\begin{array}{l}\text { Severidade, ocorrência e } \\
\text { detecção }\end{array}$ \\
\hline 8 & - & $\begin{array}{l}\text { Ações corretivas, } \\
\text { melhorias } \\
\text { recomendadas. }\end{array}$ & $\begin{array}{l}\text { NPR (Número de } \\
\text { prioridade de risco) }\end{array}$ & $\begin{array}{l}\text { NPR (Número de prioridade } \\
\text { de risco) }\end{array}$ \\
\hline 9 & - & $\begin{array}{l}\text { Distribuição de } \\
\text { tarefas e prazo }\end{array}$ & $\begin{array}{l}\text { Preparação dos } \\
\text { formulários }\end{array}$ & $\begin{array}{l}\text { Confirmar, avaliar e mensurar } \\
\text { a situação }\end{array}$ \\
\hline 10 & - & Reavaliar o NPR & $\begin{array}{l}\text { Revisão (priorizar } \\
\text { problemas) }\end{array}$ & $\begin{array}{l}\text { Refazer todos os passos acima } \\
\text { novamente }\end{array}$ \\
\hline 11 & - & - & Ações corretivas & - \\
\hline
\end{tabular}

Fonte: SAKURADA, 2001, p.22.

Os procedimentos de Teng e Ho (1996), Villacourt (1992) e Stamatis (2005) apresentados no Quadro 3, iniciam com a coleta de informações funcionais do componente ou processo-alvo da análise, utilizando-se ferramentas como o brainstorming, diagramas e fluxogramas.

As informações levantadas nas etapas iniciais do FMEA possibilitam estimar a gravidade, ocorrência e detecção (KUME, 1996; STAMATIS, 1995 apud SAKURADA, 2001) dos modos de falha. Após o cálculo do NPR (Número de Prioridade de Risco), a ser abordado mais adiante, quando o valor obtido do NPR ultrapassa o valor desejado, as ações corretivas ou preventivas são requeridas.

Neste artigo, a proposta de sistemática de utilização do FMEA para atender as especificidades das informações destinadas à avaliação da CAPES de programas de pós-graduação engloba as etapas presentes nos procedimentos de Villacourt (1992) e Stamatis (1995) do Quadro 3.

O Quadro 4 apresenta os campos de um exemplo de formulário FMEA. 
Quadro 4 - Descrição dos campos do formulário FMEA

\begin{tabular}{|c|c|c|}
\hline Item & Campo & Descrição \\
\hline 1 & $\begin{array}{l}\text { Descrição do } \\
\text { produto/processo }\end{array}$ & Informar as características do produto ou processo. \\
\hline 2 & Função & $\begin{array}{l}\text { Informar de forma concisa a intenção, propósito, meta ou objetivo do } \\
\text { componente. }\end{array}$ \\
\hline 3 & $\begin{array}{l}\text { Tipo de falha } \\
\text { potencial }\end{array}$ & $\begin{array}{l}\text { Informar o problema, preocupação, oportunidade de melhoria, falha. Podendo } \\
\text { existir mais de uma falha por função. }\end{array}$ \\
\hline 4 & $\begin{array}{l}\text { Efeito de falha } \\
\text { potencial }\end{array}$ & $\begin{array}{l}\text { Descrever as consequências que surgem no sistema causadas pelos modos de } \\
\text { falha. }\end{array}$ \\
\hline 5 & $\begin{array}{l}\text { Causa de falha } \\
\text { potencial }\end{array}$ & $\begin{array}{l}\text { Descrever a causa geradora do modo de falha. Pode estar no componente, nos } \\
\text { componentes vizinhos, no ambiente. }\end{array}$ \\
\hline 7 & Ocorrência & $\begin{array}{l}\text { Ocorrência é um índice que corresponde a um número estimado das falhas que } \\
\text { poderiam ocorrer. Deve ser baseado ou na causa ou no modo de falha. }\end{array}$ \\
\hline 6 & Gravidade & $\begin{array}{l}\text { Severidade é um índice que indica quão sério é o efeito do modo de falha } \\
\text { potencial. A severidade sempre é aplicada sobre o efeito do modo de falha. Há } \\
\text { correlação direta entre o efeito e a severidade. Quanto mais grave e crítico é o } \\
\text { efeito, maior é o índice de severidade. }\end{array}$ \\
\hline 8 & Detecção & $\begin{array}{l}\text { Detecção é a probabilidade de que os sistemas de controle detectem a falha } \\
\text { (causa ou modo de falha) antes que ela atinja os clientes (internos ou externos). }\end{array}$ \\
\hline 9 & $\begin{array}{l}\text { Número de } \\
\text { prioridade de risco }\end{array}$ & $\begin{array}{l}\text { É o índice resultado do produto do índice de ocorrência, de severidade e de } \\
\text { detecção. Este valor define a prioridade da falha. É usado para ordenar } \\
\text { (classificar) as deficiências do sistema. }\end{array}$ \\
\hline 10 & Ações recomendas & $\begin{array}{l}\text { Nenhum FMEA deve ser feito sem nenhuma ação recomendada. A ação } \\
\text { recomendada pode ser uma ação específica ou um estudo mais adiante. }\end{array}$ \\
\hline 11 & Status & $\begin{array}{l}\text { Só porque algo foi recomendado não significa que algo foi feito. É imperativo } \\
\text { que alguém siga as recomendações para determinar se elas foram direcionadas } \\
\text { adequadamente, e, ou, se é necessário fazer atualizações nestas ações. }\end{array}$ \\
\hline
\end{tabular}

Fonte: Adaptado de Sakurada, 2001.

De acordo com Sant 'Anna e Pinto Júnior (2011), o formulário do FMEA constitui-se não só para o fim precípuo da análise, a eliminação de falhas, mas também para a geração de conhecimento.

O número de prioridade de risco (NPR) atribuído a cada falha é quantificado no FMEA por meio de um índice derivado de valores atribuídos segundo três critérios de avaliação específicos: gravidade $(\mathrm{G})$, ocorrência (O) e detecção (D) da falha.

Para a estimativa de gravidade, ocorrência e detecção são atribuídos valores de 1 a 5 , sendo 1 para menor gravidade e menor ocorrência. Já para detecção, o valor 1 é atribuído à probabilidade muito alta de modo de falha ser detectado. Mais detalhes sobre a atribuição de valores podem ser obtidos em Stamatis (2005). Atribuídos esses valores, é possível calcular o Número de Prioridade de Risco (NPR), que é obtido pela multiplicação dos valores da gravidade, ocorrência e detecção.
Considerando a simplicidade e o baixo custo de execução do FMEA (ZAMBRANO; MARTINS, 2007; PINHO; AZEVEDO, 2008), este artigo apresenta uma proposta baseada no FMEA para análise de falhas das informações enviadas para a CAPES.

\section{Metodologia}

Para o artigo foi adotada a análise documental na base de dados da CAPES, conforme Figura 2. Esse método de abordagem qualitativa tem como principal vantagem, de acordo com Fernandes e Gomes (2003), o fato de os documentos constituírem uma rica e estável fonte de dados, que sobrevive ao longo do tempo. 


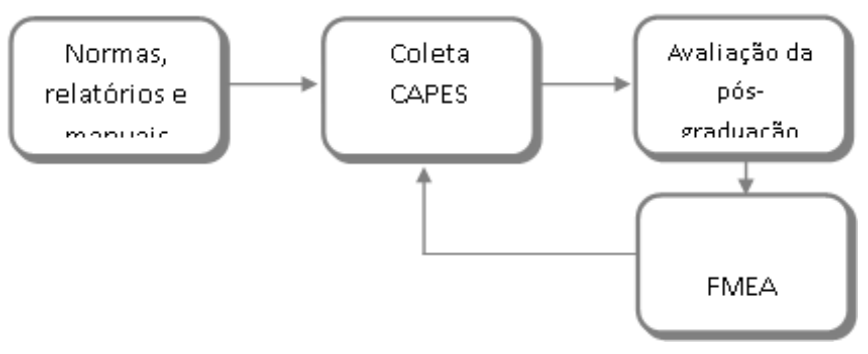

Figura 2 - Método de pesquisa.

Fonte: Elaboração própria.

A fonte de documentos utilizada na pesquisa consistiu do levantamento no site da Coordenação de Aperfeiçoamento de Pessoal de Nível Superior (CAPES) de documentos, como normas, manuais, formulários e relatórios, sobre a avaliação de programas de pós-graduação e o aplicativo Coleta CAPES.

Sob a ótica da avaliação da pós-graduação, buscou-se compreender: as etapas da utilização do Coleta CAPES; as características dos dados inseridos (causa); e a finalidade dos dados exportados na avaliação (efeito). Paralelamente, estudou-se como o FMEA pode ser utilizado como alternativa para a redução de falhas e consequente melhoria no processo de coleta e exportação de dados (Figura 2), buscando aprofundar a compreensão sobre a relação entre entre os dados inseridos no aplicativo Coleta CAPES e no sistema de avaliação da pós-graduação.

Durante a realização da pesquisa documental e considerando as características do sistema de avaliação da pós-graduação, constatouse a necessidade de desenvolvimento de uma sistemática para auxiliar na aplicação do FMEA, apresentado mais adiante.

\section{Desenvolvimento da Sistemática de Uso}

Esta seção apresenta os passos para o desenvolvimento e uso da sistemática do FMEA no Coleta CAPES. Inicialmente são destacadas as especificidades do sistema de avaliação de pósgraduação e do aplicativo Coleta CAPES. Logo após, apresenta-se detalhadamente a sistemática de uso do FMEA no Coleta CAPES. Em seguida são evidenciados os elementos do FMEA que precisam ser adaptados, como formulários e as escalas de gravidade, ocorrência e detecção. Por último, é feita uma exemplificação do uso da proposta em um dos documentos temáticos do Coleta CAPES.
Este artigo fez uso do FMEA para verificação de falhas potenciais no processo de envio de informações para avaliação de programas de pós-graduação por meio do Coleta CAPES. Foi constatada a necessidade de sistematizar a utilização do método FMEA, adaptando-o às especificidades do Sistema de Avaliação da Pósgraduação e do aplicativo Coleta CAPES, como:

- Os Programas de pós-graduação do país que integram o Sistema Nacional de Pós-Graduação (SNPG) utilizam o mesmo aplicativo Coleta CAPES, requerendo a entrada do mesmo tipo de dados.

- Os dados do desempenho dos Programas de Pós-Graduação informados no Coleta CAPES são agrupados em documentos denominados "Caderno de Indicadores", disponibilizados pela CAPES para cada Comissão de Avaliação. Dessa forma, os tipos de dados resultantes do sistema (saída) são semelhantes em todos os Programas de Pós-Graduação que integram o SNPG.

- Cada Área de Avaliação determina o peso dos quesitos e itens avaliados. Logo, os dados sobre o desempenho dos programas assumem pesos diferentes de acordo com os valores atribuídos por cada uma das áreas.

Como ponto de partida para o desenvolvimento da sistemática de uso do FMEA, foi analisada a relação entre os dados inseridos (entrada) e os indicadores gerados (saída) dentro do contexto da avaliação da Pós-Graduação coordenada pela CAPES. A Figura 3 ilustra a relação entre entradas (Cadernos Temáticos) e saídas (Cadernos de Indicadores) do Coleta CAPES.

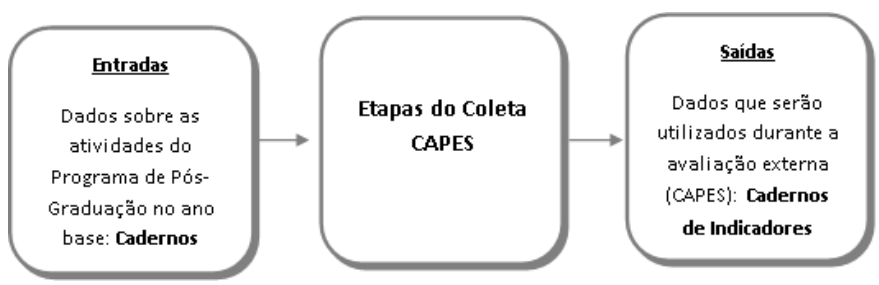

Figura 3 - Entradas e saídas do Coleta CAPES.

Fonte: Elaboração própria.

Conforme pode ser observado na Figura 3, as entradas do Coleta CAPES em seus diversos cadastros, denominados 'Cadernos Temáticos', após a exportação à CAPES, são processados e resultam em dados agrupados em relatórios denominados "Cadernos de Indicadores". Estes, por sua vez, serão utilizados pelas Comissões de 
Avaliação durante a avaliação Trienal do Programa de Pós-Graduação.

Tendo em vista as especificidades do Coleta CAPES, a Figura 4 ilustra a sistemática proposta para auxiliar os Programas de Pós-Graduação na identificação e análise das principais falhas durante o processo de levantamento e utilização do Coleta CAPES.

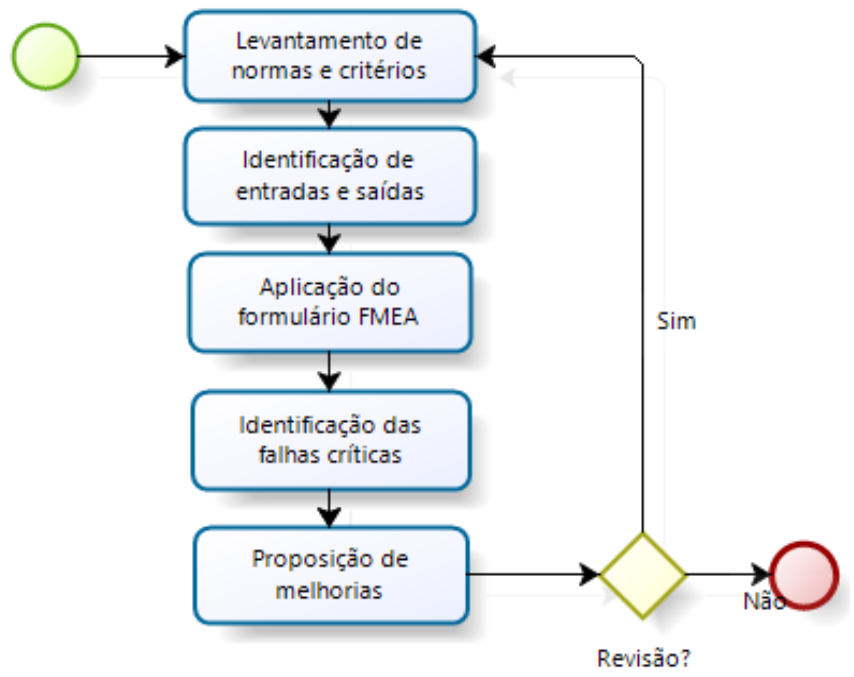

Figura 4 - Sistemática de uso do FMEA no Coleta CAPES.

Fonte: Elaboração própria.

O primeiro passo consiste na realização de levantamento sobre as normas de avaliação gerais e específicas para Área de Avaliação da CAPES, buscando compreender a finalidade das informações enviadas. A CAPES disponibiliza em sua página eletrônica subpáginas para cada área de avaliação, onde são expostos comunicados e relatórios, além de documentos relativos à avaliação trienal.

Em seguida, são determinadas as entradas e saídas dos processos do Coleta CAPES, relacionando os dados inseridos na base de dados do aplicativo e os dados apresentados em seu principal produto, o "Caderno de Indicadores" (CAPES). Tal conjunto de relatórios é disponibilizado pela CAPES em sua página eletrônica.

O passo seguinte consiste na aplicação do FMEA para análise das saídas, pois esse método tem suas principais vantagens relacionadas à sistematização, além da sua facilidade e simplicidade de uso (Ho; Liao, 2011). Após a aplicação do FMEA e identificadas as falhas críticas, deverão ser propostas ações preventivas e corretivas sobre as falhas potenciais.

Em seguida à implementação das ações, a sistemática deverá ser repetida, com a identificação de novo Número de Prioridade de Risco (NPR), considerando-se as ações corretivas e preventivas recomendadas.

É importante salientar que a sistemática proposta pode ser adaptada a outros aplicativos ou sistemas de coleta de dados que tenham como objetivo exportar dados utilizados na avaliação de programas de pós-graduação.

O formulário FMEA também foi adequado ao Coleta CAPES, conforme o apresentado no Quadro 5. Como exemplo dessa adequação, o campo de descrição do produto ou processo, que informa suas características, foi substituído pelo campo que identifica o Documento Temático do Coleta CAPES. Como exemplo de documento temático, pode-se citar a seção relativa à Produção Intelectual desenvolvida no âmbito do programa de pós-graduação.

Quadro 5 - Formulário FMEA adaptado ao Coleta CAPES.

\begin{tabular}{|c|c|c|}
\hline Item & Campo & Descricão \\
\hline 1 & $\begin{array}{l}\text { Documento } \\
\text { Temático do } \\
\text { Coleta CAPES }\end{array}$ & $\begin{array}{l}\text { Caderno Temático que } \\
\text { compõe o aplicativo Coleta } \\
\text { CAPES. }\end{array}$ \\
\hline 2 & Etapa & $\begin{array}{l}\text { Etapa de preenchimento do } \\
\text { Caderno Temático do Coleta } \\
\text { CAPES. }\end{array}$ \\
\hline 3 & $\begin{array}{l}\text { Modo de falha } \\
\text { no } \\
\text { preenchimento } \\
\text { do Caderno } \\
\text { Temático }\end{array}$ & $\begin{array}{l}\text { Principais falhas durante a } \\
\text { inserção de dados de } \\
\text { determinado Caderno } \\
\text { Temático do Coleta CAPES. }\end{array}$ \\
\hline 4 & Causa da falha & $\begin{array}{l}\text { Eventos que provocam a } \\
\text { falha }\end{array}$ \\
\hline 5 & Controles atuais & $\begin{array}{l}\text { Ações adotadas pelo } \\
\text { programa de pós-graduação } \\
\text { para controlar a ocorrência } \\
\text { de falhas. }\end{array}$ \\
\hline 7 & Gravidade & $\begin{array}{l}\text { Representa o grau de } \\
\text { gravidade da falha. }\end{array}$ \\
\hline 6 & Ocorrência & $\begin{array}{l}\text { Representa o grau de } \\
\text { ocorrência da falha. }\end{array}$ \\
\hline 8 & Detecção & $\begin{array}{l}\text { Representa o grau de } \\
\text { detecção da falha. }\end{array}$ \\
\hline 9 & NPR & $\begin{array}{l}\text { Número de Prioridade de } \\
\text { Risco, valor que define a } \\
\text { prioridade da falha, resultado } \\
\text { do produto dos índices de } \\
\text { gravidade, ocorrência e } \\
\text { detecção. As falhas com } \\
\text { maior risco devem ser } \\
\text { tratadas com prioridade. }\end{array}$ \\
\hline 10 & $\begin{array}{l}\text { Ações } \\
\text { recomendadas }\end{array}$ & $\begin{array}{l}\text { São as ações recomendadas } \\
\text { para minimizar a } \\
\text { probabilidade de ocorrência } \\
\text { das falhas. }\end{array}$ \\
\hline
\end{tabular}

Fonte: Elaboração própria. 
Além das modificações no formulário FMEA, adaptaram-se a escala qualitativa dos graus de gravidade $(\mathrm{G})$, ocorrência $(\mathrm{O})$ e detecção (D), em escala inteira de 1 a 3.

A motivação para adaptação das escalas de 1 a 3 também decorre da necessidade de adaptar o FMEA às características do processo de envio de informações para avaliação de programa de pósgraduação por meio do Coleta CAPES, considerando a influência da percepção da falha, conforme a área de avaliação na qual o programa está inserido, além das características operacionais do aplicativo que influenciam diretamente na detecção do modo de falha.

O Quadro 6 apresenta os parâmetros para determinação dos índices de gravidade, ocorrência e detecção.

Quadro 6 - Índices de gravidade, ocorrência e detecção adaptados ao FMEA para uso no Coleta CAPES.

\begin{tabular}{|c|l|l|l|}
\hline Índices & \multicolumn{1}{|c|}{ Gravidade(G) } & \multicolumn{1}{|c|}{ Ocorrência (O) } & \multicolumn{1}{|c|}{ Detecção (D) } \\
\hline 1 & $\begin{array}{l}\text { Não afeta a avaliação do } \\
\text { programa }\end{array}$ & Falha é improvável & $\begin{array}{l}\text { Falha detectável durante o uso do Coleta } \\
\text { CAPES. }\end{array}$ \\
\hline 2 & $\begin{array}{l}\text { Afeta negativamente a avaliação } \\
\text { qualitativa }\end{array}$ & Falha ocorre isoladamente & $\begin{array}{l}\text { Falha detectável durante a conferência } \\
\text { dos relatórios dos dados inseridos no } \\
\text { Coleta CAPES. }\end{array}$ \\
\hline 3 & $\begin{array}{l}\text { Afeta negativamente a avaliação } \\
\text { quantitativa }\end{array}$ & Falha ocorre frequentemente & $\begin{array}{l}\text { Falha não detectável durante a utilização } \\
\text { do Coleta CAPES e, ou, durante a } \\
\text { conferência dos dados inseridos no } \\
\text { Coleta CAPES. }\end{array}$ \\
\hline
\end{tabular}

Fonte: Elaboração própria.

A proposta de estabelecimento de sistemática para levantar o índice de gravidade da falha considerou que cada área de avaliação (CAPES) possui liberdade em atribuir peso ao item a ser avaliado. Ou seja, as áreas de avaliação (CAPES) podem conter diferentes percepções sobre uma mesma falha.

A definição do índice de gravidade está associada em uma relação crescente aos efeitos das falhas no preenchimento do Coleta CAPES sobre a avaliação do programa de pós-graduação. Dessa maneira, na atribuição do índice de gravidade a nota 3 (três) é destinada ao modo de falha que influencia, de forma negativa, os critérios quantitativos da avaliação do programa, já a nota 2 é para quando o modo de falha influencia negativamente o resultado da avaliação do programa de pós-graduação, considerando o aspecto qualitativo. E enfim, a nota 1 deve ser atribuída ao modo de falha que não afeta negativamente a avaliação do programa. Para classificar o índice da gravidade da falha, o procedimento a ser adotado é ilustrado na Figura 5.

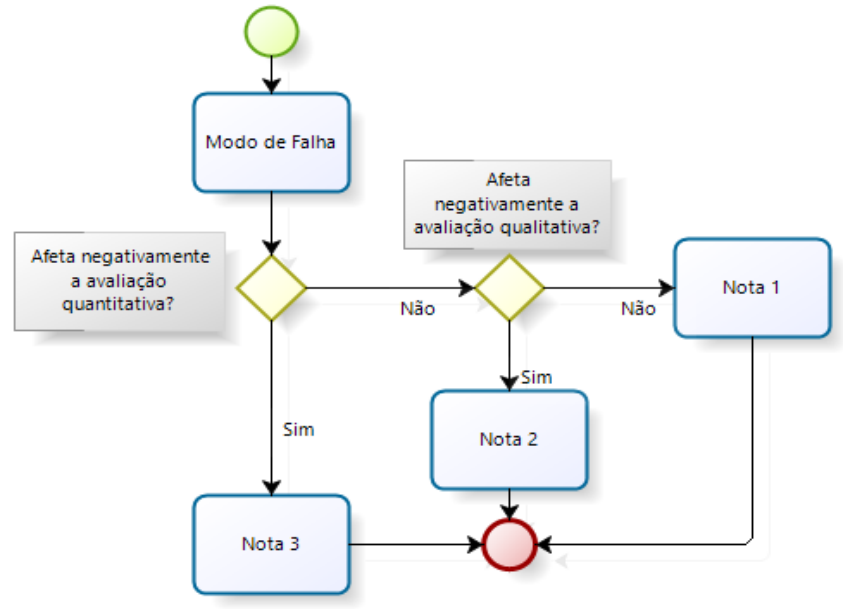

Figura 5 - Procedimento para escolha do índice de Gravidade. Fonte: Elaboração própria.

Como diretriz para atribuição do grau de ocorrência do modo de falha, deverão receber nota 3 as situações em que o modo de falha ocorre frequentemente. Já a nota 2 deverá ser atribuída ao modo de falha que ocorre de forma isolada. $\mathrm{O}$ modo de falha com ocorrência improvável receberá nota 1 .

O estabelecimento do índice de ocorrência representado na Figura 6 é influenciado pela experiência do usuário do aplicativo Coleta CAPES e pela existência ou não de histórico de registro de 
falhas.

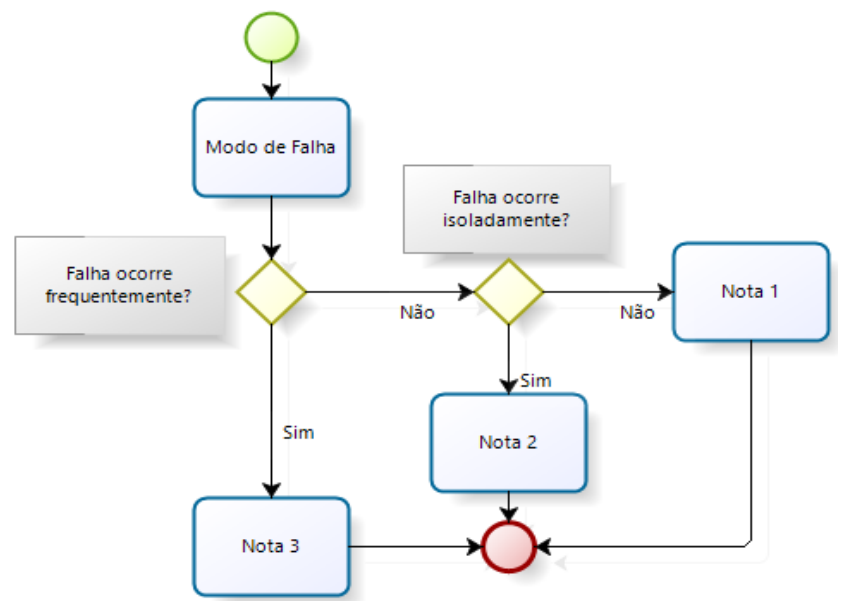

Figura 6 - Procedimento para escolha do índice de Ocorrência.

Fonte: Elaboração própria.

$\mathrm{Na}$ escala qualitativa proposta para identificação do índice de detecção (Figura 7) é considerado o momento de inserção ou conferência de dados no Coleta CAPES. Nesse aspecto, o índice detecção deverá receber nota 3 quando o modo de falha não é detectável pelo programa durante o cadastro nem na conferência dos relatórios gerados pelo aplicativo. Já a nota 2 deverá ser atribuída a modo de falha, que pode ser detectado no momento da conferência dos relatórios do Coleta CAPES. Caberá a nota $1 \mathrm{em}$ modo de falhas que pode ser percebido durante a utilização do Coleta CAPES, mediante mensagens de erros ou advertências emitidas pelo aplicativo.

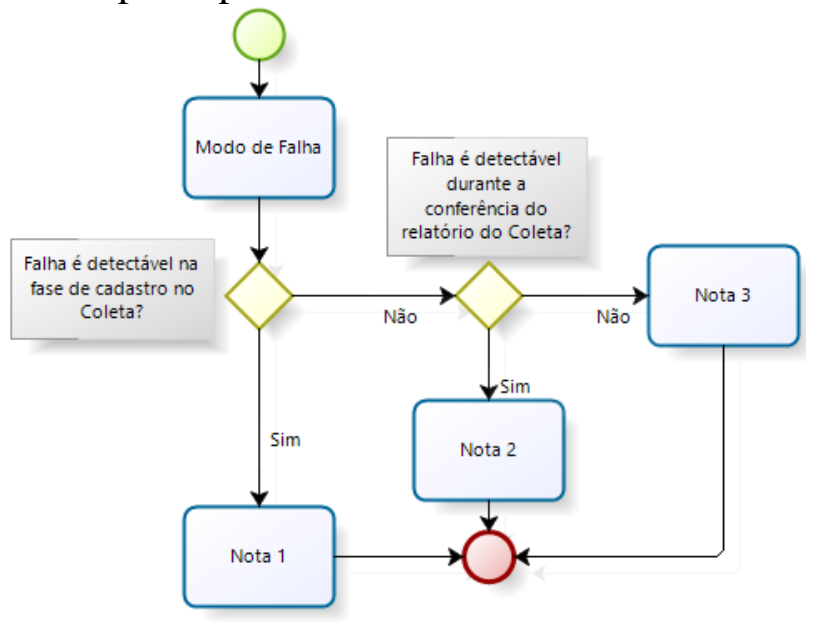

Figura 7 - Procedimento para escolha do índice de Detecção.

Fonte: Elaboração própria.
A partir do que foi apresentado, a sistemática de utilização do FMEA no Coleta CAPES deve ser utilizada nas operações no plano macro do aplicativo, considerando os documentos temáticos. A saber: Programas; Disciplinas; Cursos; Turmas; Cadastros; Trabalhos de Conclusão; Proposta do Programa; Produção Intelectual; Linhas de Pesquisa; Fluxo Discente; e Projetos (CAPES, 2009).

\section{Exemplo de aplicação no cadastro de produção intelectual}

O documento temático Produção Intelectual no Coleta CAPES (CAPES, 2011) é constituído de campos que identificam o autor e os coautores, o título da produção intelectual, dados do detalhamento da produção, dados sobre o contexto da produção na área de concentração, linha e projeto de pesquisa, bem como o vínculo com trabalhos de conclusão de curso (tese ou dissertação).

A partir do cadastro de Produção Intelectual do Coleta CAPES, será exemplificada a aplicação da sistemática de adaptação do FMEA. Para tanto, é necessário identificar a sequência do processo, conforme o exemplificado na Figura 8, que apresenta o fluxograma do módulo de Produção Intelectual. 


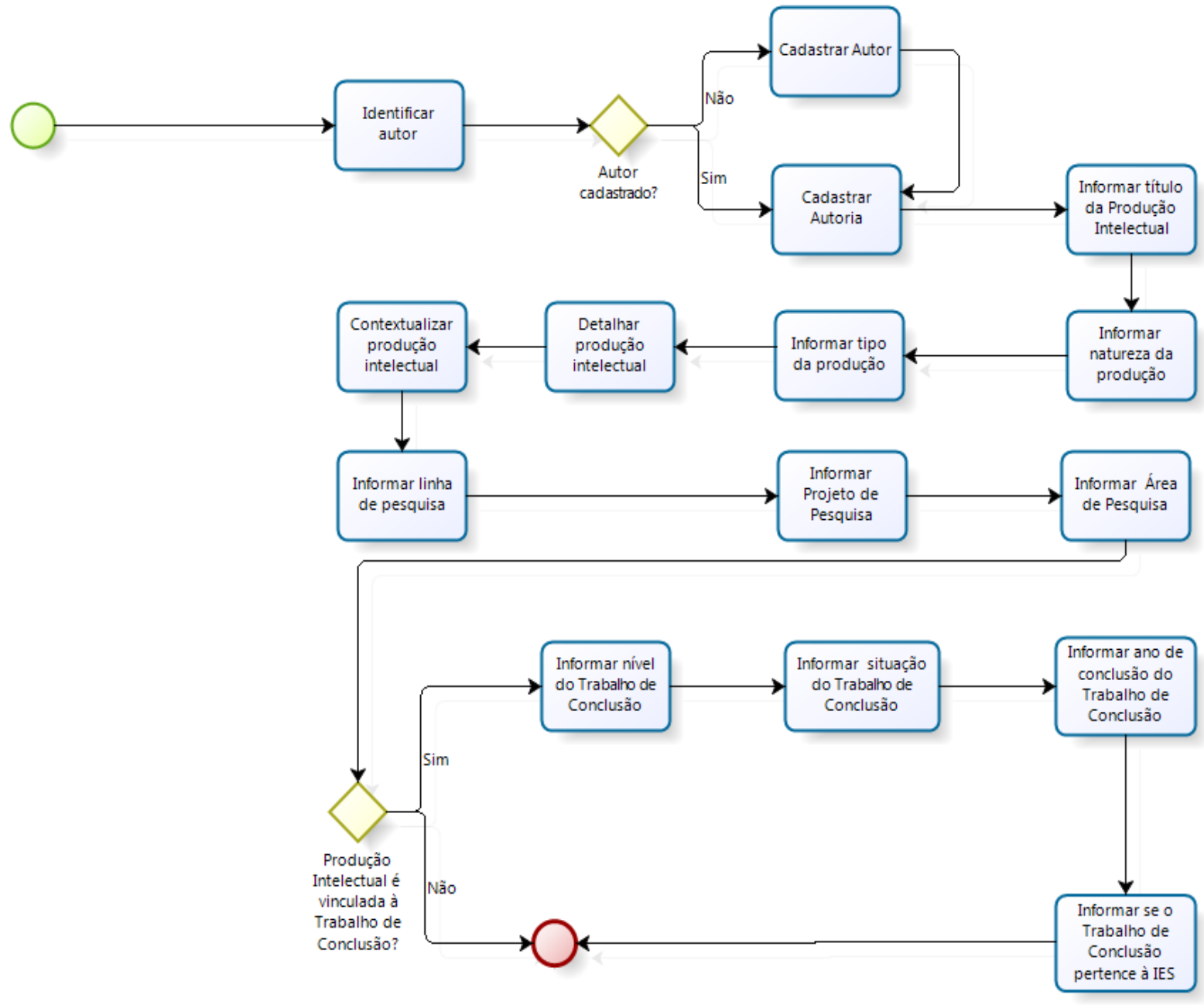

Figura 8 - Fluxograma de atividades do cadastro da Produção Intelectual no Coleta CAPES 12.0.

Fonte: Elaboração própria.

O aplicativo Coleta CAPES disponibiliza a opção de importação de dados da produção intelectual do Currículo Lattes, base de dados de currículos das áreas de ciência e tecnologia, mantida pelo Conselho Nacional de Desenvolvimento Científico e Tecnológico (CNPq), e pela agência do Ministério da Ciência e Tecnologia (MCT). No entanto, segundo a CAPES (2011b), a integração com o Lattes é um recurso adicional ao preenchimento do Coleta, não sendo seu uso obrigatório. É importante salientar que, atualmente, os dados do Currículo Lattes não satisfazem todos os campos exigidos pelo Coleta de Dados. Como exemplo, o Currículo Lattes não contempla informações sobre a contextualização da produção intelectual em Projetos e Linhas de Pesquisa do Programa de Pós-Graduação e o vínculo da produção intelectual com teses $\mathrm{e}$ dissertações, além de não fornecer dados como documentos pessoais, institucionais e formação de coautores, informações requeridas para o cadastro de coautores e membros de equipes de projetos de pesquisa.

Ainda no aspecto da importação, a produção intelectual do Currículo Lattes para o Coleta, a CAPES (2012b) alerta que serão importadas todas as produções intelectuais referentes ao ano-base contidas no currículo, mesmo que exista alguma produção da qual o referido docente ou discente não seja o primeiro autor. Diante disso, caberá ao usuário fazer os ajustes necessários no documento produção intelectual, informando corretamente a quem pertence a produção intelectual declarada.

O Currículo Lattes dos autores de produção intelectual declarada pelo programa de pósgraduação deverá ser mantido atualizado, uma vez que, no decorrer do processo de avaliação, as comissões de área consultam, com frequência, os 
dados da Plataforma Lattes (CAPES, 2011b).

De acordo com a Capes (2011b), o seu interesse é que a produção intelectual seja declarada pelo curso em que é considerado como seu "nascedouro", bem como onde existem discentes envolvidos com a produção intelectual. A produção, quando repetida, será objeto de análise das áreas de avaliação e o que a CAPES espera é que não seja considerada, durante a avaliação, em contagem dupla.

A produção intelectual a ser registrada no Coleta CAPES deverá ser aquela efetivamente concluída, não devendo ser registrados trabalhos apenas submetidos para publicação, mesmo que aceitos ou com atividades em andamento (CAPES, 2011b). A produção intelectual em andamento deve ser declarada no documento temático "Proposta do Programa”.

No registro de artigos em periódicos e anais especializados, o Coleta CAPES apresenta uma relação padronizada de periódicos e eventos. Caso o usuário não encontre o periódico ou evento, poderá cadastrá-lo. No entanto, a Capes (2012b) adverte que o cadastro de forma inconsistente poderá implicar não classificação no processo de qualificação (Qualis) da produção intelectual declarada pelo programa, concebido pela CAPES para classificar, de acordo com cada área de avaliação, os veículos de divulgação da produção intelectual dos programas de pós-graduação.

Ainda sobre publicações em periódicos, o aplicativo permite que até $2 \%$ de publicações sejam cadastradas sem ISSN (CAPES, 2012b).

No Coleta de Dados - CAPES também deverá ser cadastrada a produção do egresso do curso, que continuará constando no aplicativo Coleta de Dados, no cadastro de participante externo, como egresso. Segundo a Capes (2011b), o aplicativo realiza busca na base de dados pelo CPF e ano da produção intelectual, contabilizando-a como produção discente. Além disso, a produção intelectual deverá ser cadastrada uma única vez pelo programa. No caso de trabalhos múltiplos, primeiro deverá ser indicado o autor principal e, em seguida, os coautores (CAPES, 2011b).

Todos os coautores das produções do programa, que não pertencem a ele deverão ser cadastrados como participantes externos. Quanto à produção intelectual de docentes colaboradores sem coautoria de discentes e docentes permanentes do programa, ela deverá ser declarada quando desenvolvida na estrutura do programa (CAPES, 2011b).
A Figura 9 relaciona as entradas e saídas do Caderno Temático Produção Intelectual. Nessa etapa, os dados da produção intelectual do programa de pós-graduação, após processamento, gerarão como saída os indicadores de produção bibliográfica, técnica e artística, além de indicadores de produção docente.

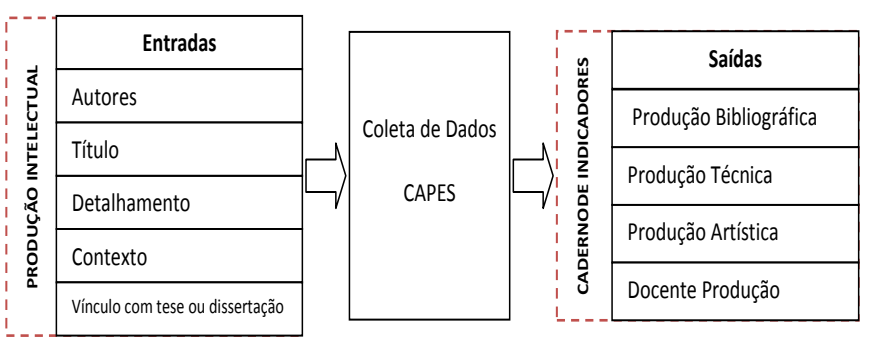

Figura 9 - Entradas e saídas do documento temático Produção Intelectual do Coleta CAPES.

Fonte: Elaboração própria.

Conclui-se que os dados registrados no documento temático Produção Intelectual estão diretamente relacionados aos indicadores de Produção Bibliográfica (PB), Produção Técnica (PT), Produção Artística (PA) e de Produção Intelectual de Docentes (DP) que ministraram disciplinas ou orientaram no ano avaliado.

No caderno de indicadores de Produção Bibliográfica (PB) são relacionadas nominalmente a produção bibliográfica do ano-base, com destaque para as cinco melhores produções selecionadas pelo programa. As produções bibliográficas são ordenadas conforme sua natureza, tipo e o Qualis do periódico ou anais, que consittuem o conjunto de procedimentos utilizados pela CAPES para estratificar a qualidade da produção intelectual dos programas.

Os autores e coautores da produção intelectual são identificados como Docente Discente ou Participante Externo do programa, conforme declarado pelo programa de pósgraduação no Coleta CAPES.

Nos cadernos de indicadores de Produção Técnica (PT) e Produção Artística (PA) são apresentadas as relações nominais da produção técnica e artística do ano-base, com destaque para as cinco melhores produções selecionadas pelo programa. As produções técnicas e artísticas são apresentadas conforme sua natureza. Assim como na produção bibliográfica, os autores e coautores também são identificados de acordo com sua classificação, como Docente, Discente ou Participante Externo do programa.

O caderno de indicadores Produção Docente 
(DP) é composto por indicadores da produção intelectual dos docentes permanentes $\mathrm{e}$ colaboradores do programa que orientaram ou ministraram disciplinas no ano-base no programa. São identificadas as categorias do docente, no anobase, sendo elas: permanente, visitante ou colaborador, conforme o vínculo declarado pelo Programa de Pós-Graduação no Coleta CAPES.

No caderno de indicadores de produção docente são apresentadas as quantidades de produção intelectual de cada docente, que orientou ou ministrou disciplina no ano-base. A produção intelectual é classificada da seguinte forma:

- Produção Bibliográfica dos tipos: Artigos Completos e Resumos, Anais, Trabalhos Completos e Resumos, Livro: (Capítulo, Integral, Coletânea).
- Produção Artística: Apresentação de Obra artística, Composição musical, Obra de Artes Visuais.

- Produção Técnica: Apresentação de Trabalho, Relatório de pesquisa e Outras.

Após compreender o objetivo do documento temático e desmembrar o processo por meio do fluxograma, identificar as entradas e as saídas do cadastro da produção intelectual, os modos de falha relacionados à operação desse cadastro devem ser listados no formulário FMEA.

O Quadro 7 apresenta modelo de modo de falhas relacionados ao preenchimento do documento temático Produção Intelectual no aplicativo Coleta CAPES.

Quadro 7 - Modelo de Formulário FMEA relacionado ao módulo Produção Intelectual do Coleta CAPES.

\begin{tabular}{|c|c|c|c|c|c|c|c|c|c|}
\hline $\begin{array}{l}\text { Documento } \\
\text { Temático } \\
\text { do Coleta } \\
\text { CAPES }\end{array}$ & Etapa & $\begin{array}{l}\text { Modo de falha no } \\
\text { preenchimento do } \\
\text { Caderno Temático }\end{array}$ & $\begin{array}{c}\text { Causa } \\
\text { da } \\
\text { falha }\end{array}$ & $\begin{array}{c}\text { Controles } \\
\text { atuais }\end{array}$ & 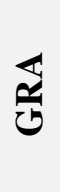 & ச & 穿 & 兴 & $\begin{array}{c}\text { Ações } \\
\text { recomendadas }\end{array}$ \\
\hline $\begin{array}{l}\text { Cadastrar } \\
\text { Produção } \\
\text { Intelectual }\end{array}$ & $\begin{array}{l}\text { Identificação } \\
\text { do autor }\end{array}$ & $\begin{array}{l}\text { Não cadastrar o } \\
\text { autor na categoria } \\
\text { Discente }\end{array}$ & & & & & & & \\
\hline
\end{tabular}

Fonte: Elaboração própria.

O modo de falha "Não cadastrar o autor na categoria Discente" utilizado como modelo no Quadro 7 impacta diretamente indicadores de produção de discentes autores da pós-graduação. Destaca-se que a produção intelectual de discentes da graduação, no caso de Instituição de Ensino Superior (IES) com curso de graduação na área, também deve ser declarada pelo Programa de PósGraduação. Portanto, pode-se considerar que a omissão dessa informação afeta negativamente a avaliação no seu aspecto quantitativo.

A causa-raiz relacionada ao modo de falha "Não cadastrar o autor na categoria Discente" é relacionada à ausência de dados como documentos pessoais e institucionais, não permitindo a correta identificação de autores e coautores discentes, especialmente quando estes pertencem ao curso de graduação (no caso de IES com curso de graduação na área). A ausência desses dados impossibilita o cadastro adequado desses autores ou coautores discentes de forma que venham a contribuir para o cálculo de indicadores de produção discente do programa de pós-graduação.

Em seguida, devem-se identificar os controles e definir os valores de Gravidade $(\mathrm{G})$, Ocorrência (O) e Detecção (D), possibilitando a atribuição dos valores de Número de Prioridade de Risco (NPR). Assim, o programa de pós-graduação poderá priorizar as deficiências do processo de envio de informações à CAPES, propondo ações corretivas e preventivas nas causas de modos de falhas críticas.

\section{Conclusões}

O principal objetivo deste artigo foi desenvolver uma proposta de análise de falhas das informações destinadas à avaliação de Programas de Pós-Graduação stricto sensu. Para tanto, foi proposta uma sistemática baseada no FMEA para detecção e priorização de falhas potenciais na utilização do aplicativo Coleta CAPES para declarar as atividades desenvolvidas pelo programa de pós-graduação em determinado ano.

A adaptação do FMEA numa aplicação na área de serviços foi desafiante, mas o uso do mapeamento dos processos se mostrou adequado para avançar na aplicação. Além disso, a elaboração 
de uma escala de 1 a 3 para os graus de gravidade, ocorrência e detecção juntamente com um quadro descritivo de cada valor facilitam ainda mais a aplicação do FMEA adaptado, servindo como diretriz para a atribuição dos índices de gravidade, ocorrência e detecção.

Uma das dificuldades encontradas foi $\mathrm{o}$ tempo necessário para o levantamento das normas e critérios adotados na avaliação de programas de pós-graduação no contexto da área na qual se insere o programa, bem como na identificação da relação de dados considerados como entradas e saídas no contexto do aplicativo Coleta CAPES. Entretanto, a compreensão das normas e critérios utilizados no Sistema de Avaliação coordenado pela CAPES é essencial, e o tempo despendido nessa atividade deve ser encarado como investimento para $o$ desenvolvimento e autoconhecimento do programa.

Como vantagem da sistemática, cita-se a possibilidade de replicação, mesmo em situações de adoção pela CAPES de novos aplicativos, em substituição ao Coleta CAPES ou sistemas de transmissão de dados. A adequação é possível desde que os dados de entradas e saídas sejam investigados pelo programa de pós-graduação.

Outra vantagem em relação à sistemática é que a utilização do FMEA para o levantamento e priorização dos riscos pode propiciar o aprendizado e a geração de conhecimento entre as pessoas envolvidas na coleta de dados, como gestores, docentes e funcionários dos programas de pósgraduação. Esse aprendizado pode resultar na reflexão e análise crítica sobre o papel dessa informação no processo de avaliação do programa de pós-graduação.

Como recomendação para pesquisas futuras, sugere-se a aplicação da sistemática em programas de pós-graduação, bem como o seu teste em programas de pós-graduação interessados em analisar e realizar ações para minimizar as falhas detectadas.

\section{Referências}

BARROS, Aluísio JD. Produção científica em saúde coletiva: perfil dos periódicos e avaliação pela Capes. Revista Saúde Pública, v. 40, p. 4349, 2006. Número especial.

BARROS, F. F.; MILAN, M. Qualidade operacional do plantio de cana-de-açúcar. Bragantia, v. 69, n. 1, p. 221-229, 2010.

BRASIL. Capes. Coleta de dados 12.0, 2011a.
Disponível em: <http://coleta.CAPES.gov.br/> . Acesso em: 12 ago. 2011.

\section{Capes. Manual do usuário coleta de} dados 12.0, 2009. Disponível em: <http://www.capes.gov.br/images/stories/download/ coletadados/Manual_do_Usuario_Coleta_12.pdf > Acesso em: 12 ago. 2011.

Capes. Manual do usuário coleta de dados 12.0 - Versão Completa, 2012a. Disponível em:

$<$ http://capes.gov.br/images/stories/download/coleta dados/Manual-do-Usuario_Coleta12_AposPort02janeiro2012.pdf>.

\section{Capes. Manual simplificado do usuário}

coleta de dados 12.0, 2012b. Disponível em: <http://www.capes.gov.br/images/stories/download/ coletadados/ManualSimplificado_ColetaDeDados1 2_24jan12.pdf>.

Capes. Missão e história, 2012c. Disponível em: <http://www.capes.gov.br/sobre-acapes/historia-e-missao>.

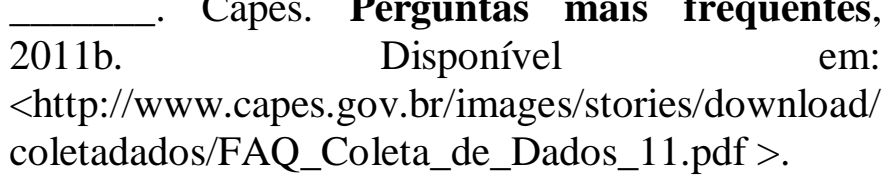

Capes. Plano nacional de pósgraduação. 2011-2020, 2010b. Disponível em: < http://www.capes.gov.br/images/stories/download/ Livros-PNPG-Volume-I-Mont.pdf> . Acesso em: 19 fev. 2011.

\section{3.}

Capes. Sistema de ficha de avaliação, <http://www.capes.gov.br/avaliacao/sistema-deficha-de-avaliacao.>. Acesso em: 02 fev. 2013.

BRASIL. Lei $\mathbf{N}^{\circ} \mathbf{8 . 4 0 5}$, de 9 de janeiro de 1992 . Disponível em: $<$ http://www.planalto.gov.br/ccivil_03/leis/L8405.h tm>.

DURHAM, E. R. A institucionalização da Avaliação. In: DURHAN, E. R.; SCHWARTZMAN, S. (Org.). A valiação do ensino superior. São Paulo: Edusp, 1992. p. 197-207.

ERDMANN, Alacoque Lorenzini et al. A avaliação de periódicos científicos qualis e a produção brasileira de artigos da área de enfermagem. Revista Latino-americana de Enfermagem, v. 17, n. 3, p. 403-409, 2009.

FERNANDES, J. M. R.; REBELATO, M. G. 
Proposta de um método para integração entre QFD e FMEA. Gestão \& Produção, v. 13, n. 2, p. 245259, 2006.

FERNANDES, L. A.; GOMES, J. M. M. Relatórios de pesquisa nas ciências sociais: características e modalidades de investigação. Contexto, Porto Alegre, v. 1, p. 71-92, 2003.

GAMA, A. A. S.; CADORE, S.; FERREIRA, V. F. Avaliação dos programas de pós-graduação em química no Brasil: versão 2002. Química Nova, v. 26, n. 4, p. 618-624, 2003.

GUZZON, Samanta de Oliveira. Proposta de análise quantitativa de confiabilidade a partir de dados qualitativos provenientes da FMEA. 2009. 119 f. Dissertação (Mestrado em Engenharia de Produção) - Universidade Federal do Rio Grande do Sul, Porto Alegre, 2009.

HECKERT, Cristiano Rocha; FRANCISCHINI, Paulino Graciano; ROTONDARO, Roberto G. QS9000: a ISO já não é o bastante. Produção, v. 8, n. 1, p. 5-16, 1998.

HO, C. C.; LIAO, C.-J. The use of failure mode and effects analysis to construct an effective disposal and prevention mechanism for infectious hospital waste. Waste Management, v. 31, n. 12, p. 26312637, 2011.

HORTALE, Virginia Alonso; MOREIRA, Carlos Otávio Fiúza. Autoavaliação nos programas de pósgraduação na área da saúde coletiva: características e limitações. Ciência \& Saúde Coletiva, Rio de Janeiro, v. 13, n. 1, 2008.

MACCARI, Emerson Antonio et al. Sistema de avaliação da pós-graduação da CAPES: pesquisaação em um Programa de Pós-Graduação em Administração. Revista Brasileira de PósGraduação, Brasília, v. 5, n. 9, p. 171-205, 2008.

MACHADO, F. A.; ZAHER, H. Pitfalls of artificial grouping and stratification of scientific journals based on their Impact Factor: a case study in Brazilian Zoology. Zoologia, v. 27, n. 4, p. 493502, 2010.

MARCHLEWSKI, C.; SILVA, P. M. da; SORIANO, J. B. A influência do sistema de avaliação Qualis na produção de conhecimento científico: algumas reflexões sobre a Educação Física. Motriz, v. 17, n. 1, p. 104-116, 2011.

MENEGHINI, R. Citations to papers from Brazilian institutions: a more effective indicator to assess productivity and the impact of research in graduate programs. Brazilian Journal of Medical and Biological Research, v. 44, n. 8, p. 738-747, 2011.

MINAYO, Maria Cecília. Pós-graduação em Saúde Coletiva de 1997 a 2007: desafios, avanços e tendências. Ciência \& Saúde Coletiva, v. 15, n. 4, p. 1897-1907, 2010.

MUNARI, D. B. et al. The setting of research production by nursing and management graduate programs in Brazil. Revista da Escola de Enfermagem da USP, São Paulo, v. 45, p. 15431550, 2011. Número especial.

PINHO, Lorena de Andrade; AZEVEDO, T. C. FMEA: análise do efeito e modo de falha em serviços: Uma metodologia de prevenção e melhoria dos serviços contábeis. ABCustos Associação Brasileira de Custos, v. 3, n. 1, p. 120, 2008.

PINTO, Angelo C.; CUNHA, Andréa S. Avaliação da pós-graduação da área de química na CAPES e a internacionalização das revistas da Sociedade Brasileira de Química: Journal of the Brazilian Chemical Society e Química Nova. Química Nova, v. 31, n. 8, p. 2221-2226, 2008.

ROOS, Cristiano et al. Aplicação da ferramenta FMEA: Estudo de caso em uma empresa do setor de transporte de Passageiros. Tecno-Lógica, v. 11, p. 29-32, 2007.

ROSA, L. C.; GARRAFA, Marcos. Análise dos modos de falha e efeitos na otimização dos fatores de produção no cultivo agrícola: subprocesso colheita da canola. Gestão \& Produção, v. 16, n. 1, p. 63-73, 2009.

RUIZ, M. A.; GRECO, O. T.; BRAILE, D. M. Fator de impacto: importância e influência no meio editorial, acadêmico e científico. Rev. Bras. Cir. Cardiovasc., v. 24, n. 3, p. 273-278, 2009.

SAKURADA, E. Y. As técnicas de análise dos modos de falha e seus efeitos e análise da árvore de falhas no desenvolvimento e na avaliação de produtos. 2001. Dissertação (Mestrado em Engenharia Mecânica) - Universidade Federal de Santa Catarina, Florianópolis, 2001.

SANTANNA, Annibal Parracho; PINTO JUNIOR, Roberto Paulo da Silva. Composição probabilística no cálculo das prioridades na FMEA. Sistemas \& Gestão, v. 5, n. 3, p. 179-191, 2011.

SANTOS, Ana Lúcia Felix; AZEVEDO, Janete 
Maria Lins. A pós-graduação no Brasil, a pesquisa 309, 2007. em educação e os estudos sobre a política educacional: os contornos da constituição de um campo acadêmico. Revista Brasileira de Educação, v. 14, n. 42, p. 534, 2009.

SPINAK, Ernesto. Indicadores cienciometricos. Ciência da Informação, v. 27, n. 2, p. 141-148, 1998.

STAMATIS, D. H. Failure mode and effect analysis: FMEA from theory to execution. Wisconsin: ASQ Quality Press, 1995. 494 p.

STEINER, João E. Qualidade e diversidade institucional na pós-graduação brasileira. Estudos Avançados, v. 19, n. 54, p. 341-365, 2005.

TESS, B. H. et al. Assessing the scientific research productivity of a brazilian healthcare institution: a case study at the Heart Institute of Sao Paulo, Brazil. Clinics, v. 64, n. 6, p. 571-576, 2009.

VIACAVA, Francisco. Produção científica dos cursos de pós-graduação em saúde coletiva no período 1998-2006. Ciência \& Saúde Coletiva, v. 15, n. 4, p. 1977-1988, 2010.

VIANNA, William Barbosa; ENSSLIN, Leonardo; GIFFHORN, Edilson. A integração sistêmica entre pós-graduação e educação básica no Brasil: Contribuição teórica para um "estado da arte". Ensaio: Avaliação e políticas públicas em Educação, v. 19, n. 71, p. 327-344, 2011.

ZAMBRANO, T. F.; MARTINS, M. F. Utilização do Método FMEA para avaliação do risco ambiental. Gestão \& Produção, v. 14, n. 2, p. 295-

Artigo recebido em: 10/02/2013.

Artigo publicado em: 11/08/2013. 